\title{
Competitividade da Carne Bovina Brasileira no Comércio Internacional (1994-2002)
}

\author{
Taize de Andrade Machado* \\ Adayr da Silva Ilha \\ Luciane da Silva Rubin
}

Resumo: 0 presente artigo tem como meta analisar a evolução da competitividade da carne bovina do Brasil e dos blocos União Européia e Nafta, no período de 1994-2002. Para mensurar a evolução da competitividade da carne bovina, optou-se por calcular o Índice de Competitividade Revelada (ICR). A hipótese básica de trabalho é de que o desempenho dos países desenvolvidos no comércio internacional é condicionado pelas políticas protecionistas, caracterizando uma "competitividade forçada". Os resultados encontrados para o Brasil, Nafta e União Européia, verificou-se que o Brasil não perdeu competitividade, apesar do protecionismo da União Européia e Nafta. A União Européia e o Nafta apresentaram um ICR baixo em relação ao ICR brasileiro, entretanto o índice dos dois blocos vem crescendo e um dos motivos deve ser a proteção que os países desenvolvidos garantem aos produtores locais.

Palavras-chave: Competitividade, Carne Bovina, Brasil, União Européia, Nafta.

Abstract: This article aims at analyzing the Brazilian, the European Union and NAFTA blocks beef market competitiveness evolution in the period of 1994-2002. To measure the beef competitiveness evolution we decided for calculating the Revealed Competitiveness Index (RCI). We make an attempt to verify this hypothesis indirectly by identifying who lost or increased its competitiveness in the beef market during the considered period. The results found to Brazil, NAFTA and the European Union demonstrated that Brazil, despite the European Union and NAFTA protectionism, did not lose its competitiveness. The European Union and NAFTA presented a low RCI in comparison with the Brazilian RCI but, the indexes of both blocks, however, are increasing and, one of the reasons should be the protection.

Keywords: Competitiveness, Beef, Brazil, European Union, Nafta.

\footnotetext{
* Taize de Andrade Machado, Bacharel em Economia e aluna do Mestrado em Integração Latino-americana da Universidade Federal de Santa Maria (UFSM). E-mail: taize21@yahoo.com.br. Adayr da Silva Ilha, Orientador, Prof. Dr. do Curso de Ciências Econômicas e Mestrado em Integração Latino-americana da Universidade Federal de Santa Maria (UFSM). Email: adayr@smail.ufsm.br. Luciane da Silva Rubin, Co-orientadora, Economista. Profa. Ms. da Faculdade Metodista de Santa Maria (FAMES). E-mail: rubin@smail.ufsm.br. Recebido em 30/01/07 e aceito em 15/06/07.
} 


\section{Introdução}

O setor agrícola detém uma importância histórica no desenvolvimento da economia brasileira, atuando como fonte fornecedora de capital, mãode-obra, alimentos, matérias-primas, além de divisas através dos excedentes exportáveis. Entretanto, apesar da pauta exportadora do Brasil ser bastante diversificada, o país tem sofrido perdas de bem-estar através de políticas que subsidiam a agricultura ou através da imposição de barreiras, tanto tarifárias, não-tarifárias, fitossanitárias ou sanitárias impostas principalmente pela União Européia e Nafta.

Ao longo da década de 1980, tan to Estados Unidos quanto União Européia, principais exportadores de produtos agrícolas atualmente, aumentaram as despesas orçamentárias com o setor, o que possibilitou a expansão de sua participação no mercado internacional. Entretanto, nas economias mais pobres, as sucessivas crises econômicas impediram políticas setoriais de ajuda. As políticas protecionistas implantadas por países desenvolvidos fazem com que a teoria das vantagens comparativas não seja observada. Em inúmeros produtos agrícolas, partindo de condições mais adversas, as nações desenvolvidas forjaram participaçóes significativas no mercado mundial.

Para mensurar a evolução da competitividade da carne bovina nos países/blocos em estudo, optou-se por calcular o Índice de Competitividade Revelada (ICR). Este índice é um indicador abrangente porque engloba todo o comércio, ou seja, inclui as importações e as exportações. O resultado do ICR mostra se um país possui vantagem comparativa para determinado produto, confrontando sua participação na pauta exportadora e importadora mundial em relação às exportaçóes e importações de um bloco ou país, dado o mesmo produto.

O objetivo deste trabalho é analisar a evolução da competitividade da carne bovina do Brasil e dos blocos União Européia e NAFTA, no período de 1994 - 2002. A hipótese básica é que o desempenho dos países desenvolvidos no comércio internacional é condicionado pelas políticas protecionistas, caracterizando uma "competitividade forçada". 


\section{As distorções do comércio internacional e a criação da competitividade forçada}

A análise da competitividade no mercado mundial exige rompimento com os limites estreitos da concorrência perfeita, conforme a Teoria Econômica Clássica.

Partindo da idéia de Ricardo (1982), as naçóes deveriam concentrar esforços na produção de mercadorias para as quais tivessem recursos abundantes. Assim, para Machado (2000 p. 48), "O fluxo de comércio entre os países refletiria a existência de diferenças tecnológicas ou na dotação de fatores, o que estimularia a especialização produtiva nos bens em que os custos de produção fossem relativamente mais baixos”.

A produção e a comercialização de produtos a custos baixos não é mais o único fator determinante dos padrões comerciais entre as nações. De acordo com Miranda (2001), variáveis como tecnologia disponível e eficiência na sua adoção, preços domésticos, insumos de produção, taxas de câmbio e de paridade, distância dos mercados de exportação, custos de transporte, estrutura de incentivos e subsídios, barreiras tarifárias, qualidade e imagem do produto, entre outros, influenciam a competitividade.

Aliado a essas dificuldades, decorrentes dos novos paradigmas do comércio internacional, persiste o uso de instrumentos que tornam o exercício da competitividade ainda mais difícil: é o montante de subsídios que as naçóes desenvolvidas desembolsam para a produção e exportação de produtos de origem agropecuária. As principais naçóes, para alcançarem desenvolvimento e inserção externa de suas agriculturas, não apenas tiveram que superar deficiências de fatores, como também fizeram uso de políticas públicas ativas para sustentar a produção interna. Em outras palavras, não foi pelo laissezfaire que Estados Unidos e União Européia se tornaram as mais importantes potências da agricultura mundial (GONÇALVES, 2003).

Além do mecanismo de subsídio, outra dificuldade que o Brasil encontra no comércio internacional com outros países é a estrutura tarifária vigente. Segundo Thorstensen (1996), a Rodada Uruguai teve como principal objetivo reforçar e ampliar a liberalização do comércio internacional reduzindo tarifas. Entretanto, Miranda $(2001$, p. 7) salienta que "[...] como resultado houve apenas sua reestruturação e a diversificação de instrumentos de restrição ao comércio". 
Em períodos de recessão, de modo geral, crescem as pressões pela imposição de medidas de proteção comercial. A Grande Depressão, na década de 1930, acelerou o processo de intervenção do Estado no sistema econômico, caracterizado pela elevação de tarifas de importação, estabelecimento de quotas e de controles cambiais ${ }^{1}$. Castilho (1994 apud MIRANDA, 2001, p. 7) afirma que "o impacto transacionado foi grande: em 1933, esse volume correspondia a $25 \%$ do que era comercializado em 1929”.

O reaquecimento da economia mundial, após a II Guerra, foi acompanhado de intensificação dos fluxos comerciais e de uma liberalização do comércio, conduzido pelo GATT (Acordo Geral sobre Tarifas e Comércio) em suas negociaçóes multilaterais. As naçóes desenvolvidas baixaram suas tarifas alfandegárias, e as taxas de crescimento do comércio neste período foram elevadas.

De acordo com Miranda (2001), após o choque do petróleo, na década de 1970, um novo padrão de protecionismo configurou-se com a maior utilização de instrumentos não-tarifários. Pereira (1989 apud MIRANDA, 2001, p. 8) "caracteriza-o pelo seu caráter discriminatório, com a implementação de barreiras protecionistas setoriais e direcionadas a exportaçóes específicas de determinados países”. Nesse contexto, insere-se a Rodada Uruguai, encerrada em 1994, cuja declaração ministerial preconizava uma maior liberalização do comércio agrícola e a minimização dos efeitos das restriçôes sanitárias, fitossanitárias ${ }^{2}$ e outras.

A política agrícola comum da União Européia, o bloco mais protecionista atualmente, vem passando por uma série de transformaçôes desde 1992. Vários fatores ocasionaram estas transformaçóes: restrições orçamentárias, processo de alargamento da União Européia e pressóes de outros parceiros internacionais dentro das negociaçóes da Rodada Uruguai. Neste contexto, a partir de então, ocorre uma imposição de maior disciplina sobre o financiamento da produção e sobre os subsídios às exportaçôes, com redução paulatina das tarifas (THORSTENSEN, 1996).

\footnotetext{
${ }^{1}$ Por exemplo, a Lei Smoot-Hawley, de 1930, nos EUA, que elevou a alíquota média da tarifa - relação entre os direitos cobrados e valor FOB sobre as importações sujeitas à tarifa - para 53\% (CARBAUGH, 2004).

${ }^{2}$ Segundo Miranda (2001), alguns autores consideram que o termo sanitário se refere apenas a animais e fitossanitária a vegetais, outros compreendem que o termo engloba ambos. Neste trabalho, será adotado o critério de que sanitária refere-se a animais e fitossanitária a vegetais.
} 
Dessa forma, a competitividade agrícola das naçóes é explicada pela Nova Teoria do Comércio Internacional, no sentido de que as políticas públicas jogaram papel decisivo, forjando as estruturas setoriais. Criaram-se estruturas de alavancagem de oferta e de abertura de mercados, em que subsídios públicos são utilizados. A escassez de terras e mão-de-obra não consistiu em obstáculos insuperáveis, pois o progresso técnico criou terras agricultáveis e mecanizou processos, na mesma medida que políticas de exportação criaram mercados. Dessa forma, a conquista de posições competitivas de mercado na agricultura mundial revela-se como uma luta incessante contra mecanismos que distorcem o comércio internacional, caracterizadas pelas barreiras tarifárias e não-tarifárias.

Poucos países têm tanto a ganhar com a liberalização multilateral do comércio agrícola como o Brasil (JALES, 2005). O Brasil é o maior exportador mundial líquido de produtos agrícolas, detém bons índices de produtividade e apresenta potencial de expansão da produção. Na produção de carnes, o país é o primeiro no ranking entre países exportadores para carne bovina e frango. É o primeiro na exportação de suco de laranja e segundo no complexo soja.

\section{Metodologia}

Para mensurar a evolução da competitividade da carne bovina, optouse por calcular o Índice de Competitividade Revelada (CR), proposto por Carvalho (2001).

O Índice de Competitividade é calculado da seguinte forma:

$$
C R_{k i}=\ln \left[\frac{X_{k i} / X_{k r}}{X_{m i} / X_{m r}} / \frac{M_{k i} / M_{k r}}{M_{m i} / M_{m r}}\right]
$$

Onde $X$ corresponde à exportação e $M$ à importação, o subscrito $k$ referese ao produto e $i$ ao país. O subscrito $m$ refere-se ao agregado dos produtos, excluindo $k$, e $r$ ao agregado de todos os países, excluindo $i$ (CARVALHO, 2001).

O Índice de Competitividade Revelada é um indicador abrangente porque engloba todo o comércio, ou seja, inclui na análise as exportaçóes e importaçóes, constituindo-se "uma medida útil para análises agregadas quando 
produtos são exportados e importados pelo país" (CARVALHO, 2001, p. 128). Assim, a estimativa desse índice pode ser uma fonte complementar de ajuda para o estabelecimento de políticas públicas setoriais e de estratégias às empresas do setor.

O resultado do Índice da Competitividade Revelada (ICR) permite verificar se um país possui vantagem competitiva para determinado produto, confrontando sua participação na pauta exportadora e importadora nacional e mundial em relação às exportações e importaçóes de um bloco ou país, dado o mesmo produto.

Segundo Carvalho (2001, p. 128), "se $\mathrm{CR}_{\mathrm{ki}} 0$ o país revela vantagem competitiva no comércio de $k$ e, naturalmente, se $\mathrm{CR}_{\mathrm{ki}} 0$, desvantagem”.

Os dados das exportaçóes e importaçôes para o cálculo do índice $\mathrm{CR}_{\mathrm{ki}}$, no que se refere a carne bovina, são obtidos junto à Food and Agricultute Organization (FAO), e os dados sobre importaçóes e exportações totais são obtidas junto à Organização Mundial do Comércio (OMC).

\section{Resultados e discussão}

$\mathrm{O}$ índice de competitividade do Brasil revelou a supremacia brasileira no cálculo do ICR para a carne bovina, em relação aos dois blocos em estudo. Para todos os anos, exceto no período de 1994 a 1997, o Brasil teve crescimento de sua competitividade, revelando o superávit comercial que o país tem nesse produto. 


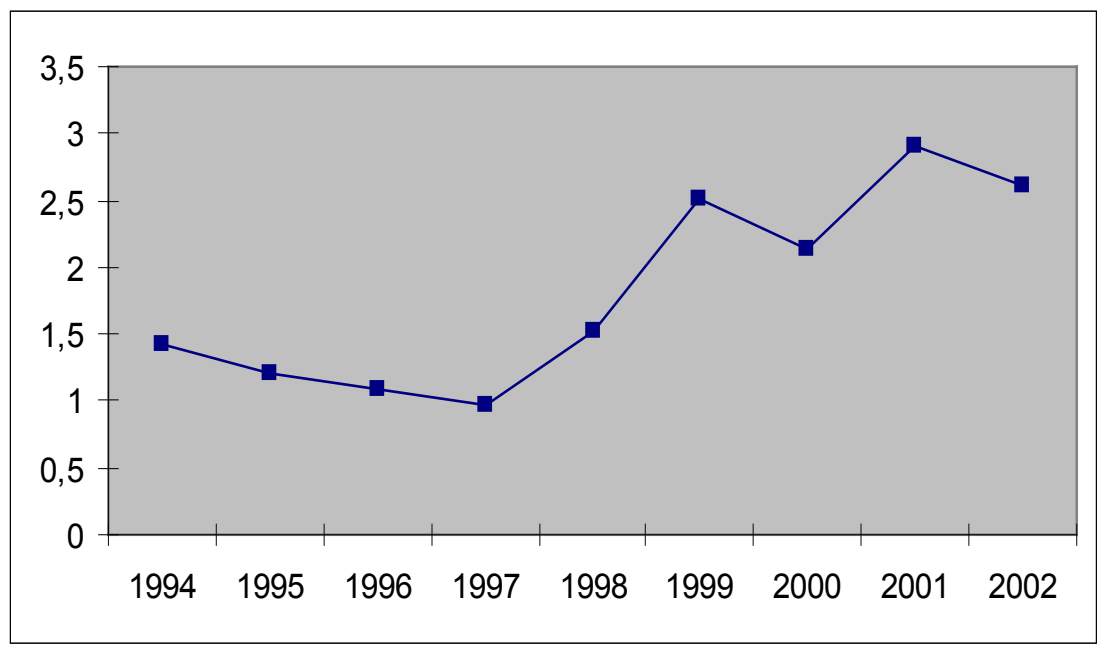

Gráfico 1 - Índice de competitividade revelada para o Brasil, 1994-2002 FONTE: Elaboração própria a partir de dados da FAO e OMC

Observa-se, através do Gráfico 1, que, de 1994 a 1997, houve perda de competitividade da carne bovina brasileira e um salto a partir de 1997. As exportaçóes de carne bovina diminuíram a partir de 1993 devido à conjunção de aumento de consumo interno (estabilidade da economia interna) e retraçáo do mercado externo (LIMA DE PAULA, FAVERET FILHO, 2001).

A partir de 1997, as exportaçóes voltaram a crescer devido à crise sanitária européia e à diminuição de impostos e sobretaxas cobradas pela Uniāo Européia (LIMA DE PAULA, FAVERET FILHO, 2001). Para Jank (2004-2005), a ascensão do agronegócio teve seu momento de inflexão a partir da desvalorização do Real, em 1999. Verifica-se desde então, uma onda de crescimento do setor. Com aumento do consumo interno, a China e outros países asiáticos entraram no mercado comprando grandes volumes de alimentos. A expansão do agronegócio neste período baseou-se em ganhos de eficiência (produtividade e exploração de economias de escala), câmbio desvalorizado e forte demanda externa.

Segundo Jank (2004-2005), entre 1997 e 2001, o Brasil vivenciou a conseqüência do pico no volume de subsídios agrícolas norte-americanos garantidos pela reversão da Lei Agrícola de 1996 dos Estados Unidos por conta 
do elevado superávit fiscal obtido pelo governo Clinton, que possibilitou a aprovação de várias leis emergenciais de ajuda aos agricultores norteamericanos. As exportaçóes brasileiras do agronegócio, que tinham atingido pouco mais de US\$ 16 bilhôes em 1997, caíram para pelo menos US\$ 13 bilhôes em 2000, em grande parte devido ao baixo preço das commodities. A partir de então, os subsídios norte-americanos passaram a ser contracíclicos, ou seja, aumentam no momento em que há queda dos preços internacionais. Isso explicaria a queda do ICR brasileiro para o ano de 2000.

Os picos de exportação da carne bovina brasileira, em 2000, refletem o embargo que a carne européia sofreu no mercado do Oriente, em função do agravamento da crise da "vaca louca". A redução dos subsídios às exportaçôes européias (julho de 2000) também foi responsável pela evolução crescente das exportaçóes brasileiras com destino aos países do Oriente Médio e Extremo Oriente.

Entretanto, no que se refere à crise da vaca louca em 1996, destaca a FAO que os efeitos sobre as exportaçôes de carne bovina a países não pertencentes à União Européia foram limitados porque o Reino Unido não era um exportador importante fora do bloco. Estas enfermidades epidêmicas não parecem haver ocasionado perturbaçóes em longo prazo no mercado.

Em 2001, o surgimento de focos de febre aftosa (embora fossem isolados) prejudicou a competitividade das exportaçóes de carne bovina brasileira.

Em relação à análise do ICR do Nafta, Gráfico 2, verifica-se que, entre 1994 e meados de 1998, o Nafta tinha um ICR negativo. A partir de 1999, houve crescimento do ICR, que pode ter sido barrado em 2001 pelo surgimento da doença da "vaca louca", e fez com que principalmente os Estados Unidos perdessem muitos mercados, entre eles a Rússia, seu principal parceiro comercial no que se refere à carne bovina.

O Nafta mostrou-se competitivo no comércio de carne bovina somente a partir de 1998 e tem aumentado sua competitividade ao longo do tempo. Segundo Lima de Paula e Faveret Filho (2001), o maior exportador de carne bovina durante a década de 1990, os Estados Unidos, mantiveram estabilidade no valor de suas exportaçóes. A partir da metade da década de 1990, os Estados Unidos passaram a aumentar suas importações, retornando, ao final da década, aos níveis de 1990, com volumes cerca de 17\% maiores, 
o que foi bastante influenciado pelo aumento da importação de carne para hambúrguer. Quanto ao Canadá, obteve aumentos expressivos de suas exportaçóes, com taxas médias anuais de $46 \%$.

O Nafta constitui-se no maior mercado mundial de consumo de carne bovina, o que de certa forma justifica os índices de competitividade encontrados.

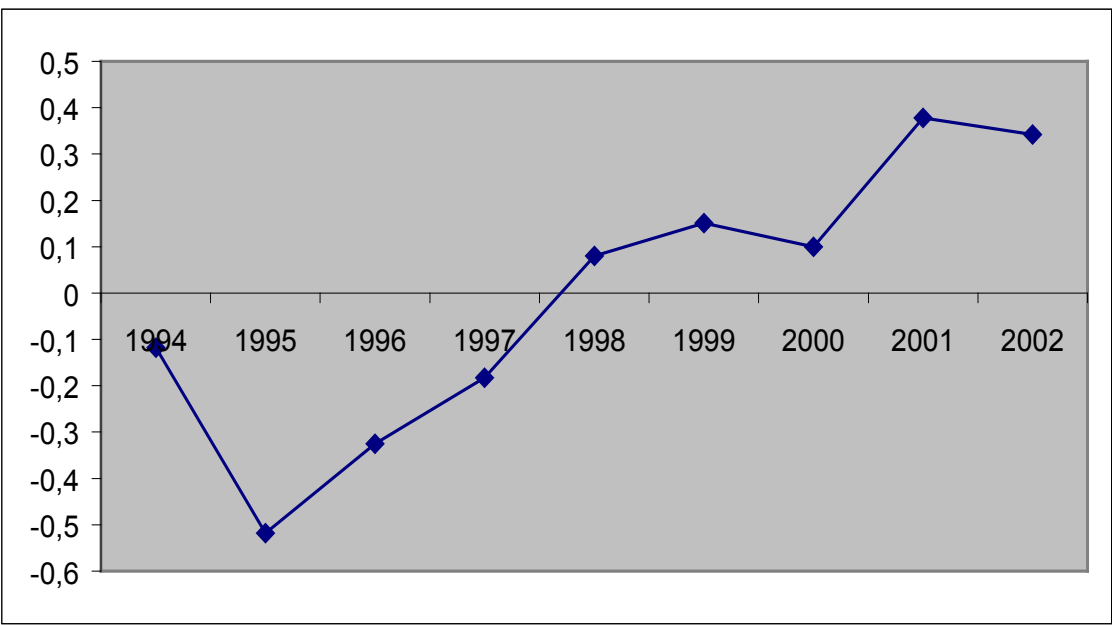

Gráfico 2 - Índice ICR para o Nafta, 1994-2002

FONTE: Elaboração própria a partir de dados da OMC e FAO.

No que se refere ao ICR da União Européia verifica-se que este tem crescido progressivamente (Gráfico 3) principalmente em anos em que há distribuição de subsídios aos produtores de carne bovina. Pode-se verificar que, a partir do ano de 2000, quando houve queda de ajuda governamental aos agropecuaristas, o ICR caiu, chegando a atingir a marca de 0,025 (em 2000 o valor de 0,08$)$. 


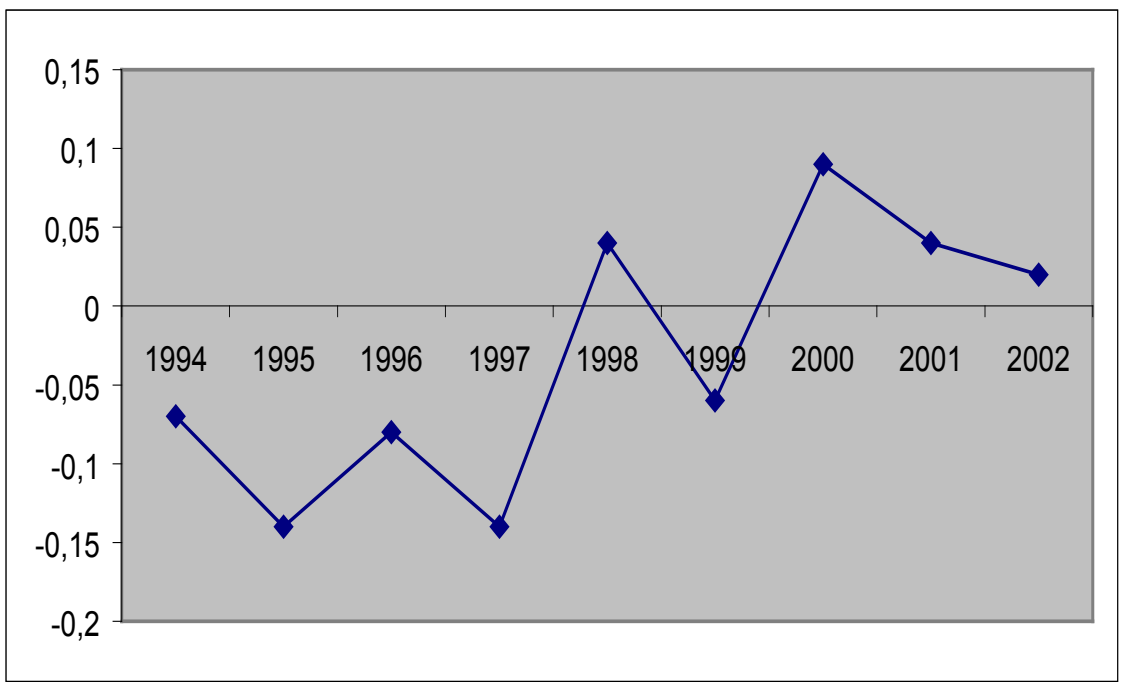

Gráfico 3 - Índice de competitividade da carne bovina para a União Européia FONTE: Elaboração própria a partir de dados da OMC e FAO.

Segundo Miranda (2001), através da PAC procurou-se interferir no mercado de carnes, de forma que o Scientific Steering Comitee (SSC) e o Comitê de Administração de Políticas Agrícolas têm tentando ajustar o Aid Price Storage (APS), para equilibrar esses estoques. Tal sistema consiste em armazenagem paga por três meses para aqueles que se dispuserem a estocar o produto. Contudo o receio de contínuos e futuros problemas como a doença da "vaca louca" tem prejudicado o resultado dessa política, afastando os pecuaristas da estocagem. Até meados de 2000, os estoques europeus encontravam-se novamente reduzidos, e o subsídio europeu às exportaçôes de carne era de US\$1600/tonelada, permitindo aos países do Bloco ofertarem carne a preços bastante competitivos, principalmente para países do Oriente, e provendo receitas elevadas aos produtores europeus. Esse fato pode ter determinado o aumento da competitividade neste período, conforme Gráfico 3. A partir de julho de 2000, esse subsídio deixou de vigorar, permitindo que países exportadores como o Brasil se tornassem mais competitivos no mercado do Oriente.

Segundo Ferreira (2000 apud MIRANDA, 2001), a justificativa da União 
Européia é de que pagamentos diretos são instrumentos mais eficientes para garantir renda ao produtor do que o suporte através de preços. Conforme o autor, o conhecimento desse programa de apoio ao pecuarista europeu é essencial para o entendimento pleno das dificuldades que países como o Brasil têm para concorrer sob condiçóes artificiais de competitividade, mesmo sendo o Brasil o maior exportador de carne bovina do mundo.

A preocupação justifica-se quando se considera que pelo menos $40 \%$ da renda do pecuarista europeu seja proveniente destes programas de apoio. Outra conseqüência é a geração de excedentes, cujo escoamento só é viável a preços competitivos, por meio dos subsídios às exportações. Dados da FAO, a partir de 1997, assinalam que a Uniāo Européia passa a ter um superávit no que diz respeito à comercialização da carne bovina e neste mesmo período o Brasil tem uma queda nas exportaçóes do produto. Dentre os vários fatores que possam ter levado a esta situação, certamente um dos fatores econômicos mais importantes foi a superproteção da União Européia em relação a este setor.

Apesar do alto volume de subsídios que ainda é repassado aos produtores, a União Européia tem diminuído os repasses. Conforme o ICONE (2005), os subsídios às exportações estão em queda: a União Européia gastou cerca de US\$ 2,5 bilhões em subsídios em 2000, quando havia gastado mais de US\$ 6 bilhóes no passado. Produtos lácteos, carne bovina, açúcar e cereais são os que recebem maior montante em subsídios às exportaçôes.

Os Estados Unidos não possuem programas diretos de apoio à produção, mas, segundo Jank (1996 apud MIRANDA, 2001), o setor se beneficia do controle das importaçóes e de políticas que afetam a produção de raçóes, além de apoio às exportaçóes ${ }^{3}$. Conforme Ferreira (2000 apud MIRANDA, 2001), o corned beef exportado para os Estados Unidos pelo Brasil recolhe um imposto de importação de 3,7\%. Além disso, a inexistência de um acordo de equivalência técnica sanitária e as exigências impostas pelo mesmo inviabilizam as exportaçóes de carnes frescas do Brasil.

O imposto para as importaçôes de carne industrializada no Japão é

\footnotetext{
${ }^{3}$ Segundo o ICONE, os EUA aplicaram, em 1998, US\$ 3,9 bilhões em créditos às exportações. A OCDE estima em US\$ 258 milhões o valor dos subsídios embutidos no crédito (6,5\% do valor total dos créditos). Austrália, União Européia dos 15 e Canadá também utilizam mecanismos de crédito às exportações. Nesses mercados, o valor do subsídio equivalente está abaixo de $2 \%$ do valor total dos créditos.
} 
ainda mais elevado (25,8\%). Além disso, o Japão não aceita o princípio da regionalização para fim de tratamento das áreas livres da febre aftosa e não permite a importação de carne in natura do Brasil.

Como se vê, o protecionismo sobre a carne bovina é amplamente utilizado por vários países e cria entraves de toda ordem para o aumento da produção e exportação brasileira.

A partir dos resultados mostrados, nota-se que as naçóes desenvolvidas como as pertencentes ao NAFTA e à União Européia têm aumentado seus índices de competitividade significativamente ao longo do período estudado. Este fato se mostra interessante ao constatar-se que esses blocos, que são industrializados, têm se especializado na produção de carne bovina.

Os resultados encontrados para o ICR e o constante aumento do valor dos subsídios agrícolas dados aos produtores de carne bovina desses blocos levam a crer que essa competitividade não é "natural", mas "forçada". Além disso, em certos períodos, como 1997 e 2000, o uso de subsídios e restriçóes técnicas e sanitárias praticadas pela União Européia e Estados Unidos, respectivamente, parecem ter influenciado na perda de competitividade na produção de carne bovina do Brasil.

\section{Conclusão}

Os resultados apontaram que o NAFTA e a União Européia tiveram aumento de sua competitividade ao longo do período, denotando um paradoxo, porque estes blocos são extremamente industrializados. Constatouse que, nos anos em que a produção foi parcialmente subsidiada, como 1997 e 2000, o índice de competitividade teve aumento significativo, sofrendo quedas ao descobrirem-se doenças como a "vaca louca", típica de produção intensiva.

Entretanto, apesar das distorçóes comerciais causadas principalmente pelo alto volume de subsídios e das restriçóes sanitárias impostas pelos blocos estudados, o Brasil mantém-se competitivo no mercado da carne bovina. Isso indica a vantagem comparativa "natural" brasileira nesta produção, pois conforme mostrado no trabalho, cerca de $40 \%$ da renda do produtor europeu de carne bovina provém de ajuda governamental. Como se vê, as políticas públicas voltadas para agricultura podem justificar o sucesso ou 
fracasso no mercado internacional, fazendo com que, muitas vezes, países em desenvolvimento como o Brasil percam espaço no comércio mundial de produtos agrícolas.

O conceito de competitividade é aqui indicado no sentido de variação na participação de um país nas exportaçóes e importaçóes de determinado produto. A metodologia deste trabalho não possibilita a identificação da razão das mudanças nas vantagens competitivas do Brasil, Nafta ou União Européia, mas serve de indicador de desempenho. $O$ índice utilizado mostra, principalmente, o peso que o produto tem na pauta exportadora de cada país, logo, como os dois blocos estudados são grandes exportadores e importadores, o índice torna-se pequeno.

A maior participação do Brasil no mercado exportador para produtos do agronegócio é um elemento em construção na relação do país com seus parceiros comerciais. O Brasil precisa continuar lutando nas rodadas de negociação da OMC em busca de uma maior liberalização comercial para a agricultura, tendo em vista que esta é uma das formas de entrada de divisas na economia do país, permitindo um maior crescimento econômico. 


\section{Referências Bibliográficas}

CARBAUGH, Robert. Economia internacional. São Paulo: Pioneira/Thomson Learnig, 2004.

CARVALHO, Maria Auxiliadora. Políticas públicas e competitividade da agricultura. Revista de Economia Política, São Paulo, v. 21, n. 1, p. 117-139, jan-mar. 2001.

GONÇALVES, José Sidnei. Competitividade da agricultura no mercado mundial globalizado: as idéias de Porter e a realidade de iniqüidades. Revista Informaçôes Econômicas, v. 33, n. 7, p. 15-36, jul. 2003.

INSTITUTO DE ESTUDOS DO COMÉRCIO E NEGOCIAÇÓES INTERNACIONAIS (ICONE). Vários. Disponível em: http://www. iconebrasil.org.br. Acesso em: nov. 2005.

JALES, Mario. Inserção do Brasil no comércio internacional agrícola e expansão dos fluxos comerciais sul-sul. Disponível em: http://www.iconebrasil.org.br. Acesso em: out. 2005.

JANK, Marcos Sawaya et al. Brasil, potência agrícola mundial. Disponível em: http://www.iconebrasil.org.br. Acesso em: jul. 2005.

- Agronegócio e comércio exterior brasileiro. Revista USP, São Paulo, n. 64, p. 14-27, dez-fev, 2004-2005. Disponível em: http: //www.iconebrasil. org.br. Acesso em: nov. 05.

LIMA DE PAULA, Sérgio Roberto; FAVERET FILHO, Paulo. Exportações de carne bovina: desempenho e perspectivas. Revista BNDES Setorial, n. 14, p. 28-46, set. 2001.

MACHADO, João Bosco M. Mercosul: processo de integração: origem, evolução e crise. São Paulo: Aduaneiras, 2000.

MIRANDA, Sílvia Helena Galvão. Quantificação dos efeitos das barreiras nãotarifárias sobre as exportaçôes brasileiras de carne bovina. 2001. $233 \mathrm{f}$. Tese (Doutorado em Economia Aplicada) - Escola Superior de Agricultura "Luis de Queiroz”, Piracicaba, 2001. Disponível em: http://www.teses.usp.br. Acesso em: nov. 2005. 
RICARDO, David. Princípios de economia, política e tributação. São Paulo: Abril Cultural, 1982.

THORSTENSEN, Vera. Desenvolvimento da cooperação econômica e das relações comerciais entre a UE e o MERCOSUL: interesses e desafios. Revista Politica Externa, v. 5, n. 1, p. 36-82, jun. 1996. 